\title{
The Economic Impact of the Mobility of the Labour Force
}

\author{
Gabriel Croitoru, Ion Stegăroiu, Valentina-Ofelia Robescu \\ Faculty of Economics, "Valahia" University of Târgoviste, Romania, , \\ croitoru.gabriel2005@gmail.com, stegaroiu.ion@yahoo.com, robescuo@yahoo.com
}

\begin{abstract}
This article wants to be a short presentation of the evolution of migration phenomenon in Europe after 2008, once the entire world met a new economic and social development, and also, the analysis of the impact of the migration and labor force mobility and of immigration in an extended Europe. It is also analyzed the dimension of this phenomenon in Romania. Using statistic methods and econometric techniques, we are going to estimate the influence of some regional indicators on the interregional migratory flows from Romania. Demography means destiny is an expression frequently used by historians, sociologists and demographers, which can also be taken as a political warning.
\end{abstract}

Keywords: mobility, migration, interregional, demography

\section{Introduction}

In the last four years there has been an increase in the migrating flows from Central and Eastern Europe to the western part of the continent, for economic reasons. The new conditions allowed the people's migration towards zones with high salaries and a smaller rate of unemployment.

Demographic change is today one of the key challenges of sustainable development with many countries experiencing a decline in the urban population over the past few decades due to suburbanization and deindustrialization, which has resulted in a wide range of socio-economic issues (e.g. increased unemployment rate, decrease in revenue, degradation of properties). Mainly due to falling fertility rates, many cities and regions are likely to continue to "shrink" in the coming decades, even with some increases in population due to migration (from within or outside the country) [1]. An important characteristic of the migration in the countries from Central and Eastern Europe is the repartition of ethnic minorities. The most important ethnic migratory movement has been that of the Romany backs to Romania, who even receive a sum of money to return to their native country, see the case of French State. The ethnic conflicts from various regions continued to be the source of the present and potential migration; at present, most of the countries from Central and Eastern Europe are considered to be stable and for this reason, the applications for asylum made by people from these countries have been rejected, fact that has contributed to a decrease in the number of permanent migrants towards Western Europe, as opposed to the increase in the number of temporary migrants.

As for the free circulation of workers, the E.U has imposed to all the States, Romania included, a period of transition, after adhesion, between two and seven years, proposing the following arrangement, "the Member States will 
continue to apply the national measures within a period of two years".

According to the surveys on the labor market published on $12^{\text {th }}$ September 2012, in February - April 2012 and May-July 2012, the labor force increased by 236.000 , the number of unemployment went down by 7.000 and the number of inactive people, with ages between 16 and 64, decreased by 181.000. Between March and May 2008, hen the number of unemployed people reached a recession of pre peak of 29.570.000, and May-July 2012: the number of full-time workers decreased by 640.000 ; the number of part time workers increased by 628.000 ; the number of unemployed increased by 978.000; the number of inactive persons, with ages between 16 and 64, decreased by 60.000 (figure 1 ).

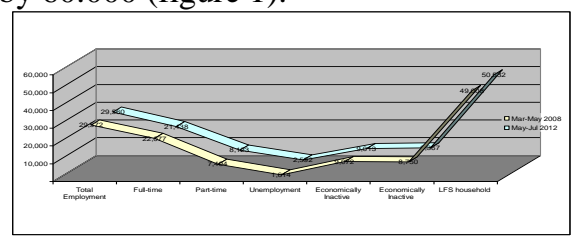

Fig. 1. Changes in number of people in labour market statuses between March to May 2008 and May to July 2012, seasonally adjusted [2], Source: Labour Force Survey - Office for National Statistics

For Romania, the development of the work force in diversified activities is characterized by the distribution of labor resources mostly in the inefficient sectors, such as: agriculture and industry. The main issues in labor force structure in Romania as compared to EU 25 refer to: the large and slightly decreasing number of people in employment in 2011, 28.6\% from all the population in employment was concentrated in agriculture, $28.8 \%$ in industry and constructions, and $42.6 \%$ in services.

According to the International Labour Bureau, the Romanians have the tendency to leave shortly the country to find a job abroad. Also, the Romanians have a high inclination towards migrating for average employment periods (a few years), long compared to other countries from Central and Eastern Europe (figure 2).

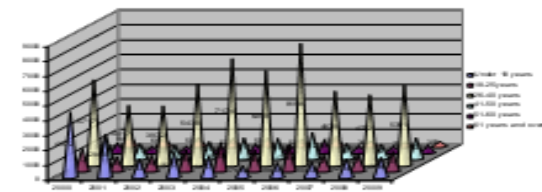

Fig. 2: Changes in the number of emigrants on age groups. (Romanian citizens who have got permanent residence abroad), Source: Statistic Annual of Romania, 2012, (INS) [3].

The analysis of the effects of migratory flows from Romania in the context of the E. $U^{\prime}$ extension takes into account all the economic dimensions of the quality of member of E.U., so it should be made in the general context, which regards at the same time the liberalization of commercial flows of capital and labor force. Romania's economic development, after acquiring the quality of E.U member, was influenced by the migratory flows through human capital exit, due to the brain drain, and the reversing financial flow associated with emigration, i.e. the sums of money sent to Romania by the emigrants.

\section{Methodology of research. Presentation of the mathematic model}

Let us consider, in the following 2 sets of data, in view of checking the connection between regional behavior/model of migration $\mathrm{y}=\left(\mathrm{y}_{\mathrm{i}}\right), \mathrm{i}=1$, and the regional indices with impact on the change in population $\left(\mathrm{X}=\mathrm{X}_{\mathrm{i}}\right)$, i 1.9. To make a choice, we will suppose that $\mathrm{y}$ is exogenous variable, and $\mathrm{x}$ is endogenous. In addition, $y$ is inconstant. An econometric linear model between $y$ and $\mathrm{x}$ consists in the determination of $\mathrm{a}$ relation like: $Y$ If the first two forms the above expression: $\alpha X+\beta$ bear the name 
of determinist component of this one, the last: $\varepsilon$ is called stochastic component of this one. For each pair of data we will have a relation like: $Y_{i}=\alpha X_{i}+\beta+\varepsilon_{i}$, i. 1.9 ,

Where $\varepsilon_{\mathrm{i}}$ is the residual variable corresponding to the pair $\left(\mathrm{X}_{\mathrm{i}}, \mathrm{Y}_{\mathrm{i}}\right)$.

To construct the model, we will presume a series of conditions that are to be achieved, such as:

- $\mathrm{F}\left(\varepsilon_{\mathrm{i}}\right)=0$ จi $\overline{1, n}$ - the mean/average of each residual variable (of nonconformity deviation of the model from the linear function) is null (zero).

- The residual variables have a normal distribution of average 0 (see the previous condition) and the same dispersion $\mathrm{D}\left(\varepsilon_{\mathrm{i}}\right)=\sigma^{2} \quad \nabla \mathrm{i} \quad \overline{1, n}$ (the hypothesis of homoscedasticity, as opposed to heteroscedasticity, when dispersions depend on $\mathrm{i}$ );

- $\mathrm{C} \varepsilon_{\mathrm{i}}, \varepsilon_{\mathrm{j}}=0, \nabla \mathrm{i} i \mathrm{j} \overline{1.12}$ - the residual variables are not correlated (practically we do not have any dependence between residues). As $\mathrm{C} \varepsilon_{\mathrm{i}}, \varepsilon_{\mathrm{j}}=\mathrm{F}\left(\varepsilon_{\mathrm{i}}, \varepsilon_{\mathrm{j}}\right)-\mathrm{F}\left(\varepsilon_{\mathrm{i}}\right) \mathrm{F}\left(\varepsilon_{\mathrm{j}}\right)=\mathrm{F}\left(\varepsilon_{\mathrm{i}}, \varepsilon_{\mathrm{j}}\right)$ (from the first condition), it results equivalence $\mathrm{F}\left(\varepsilon_{\mathrm{i}}, \varepsilon_{\mathrm{j}}\right)=0$;

- $\mathrm{C}_{\varepsilon_{\mathrm{iY}}}=0 \quad \forall \mathrm{i} \quad \overline{1, n}$ - the exogenous variable is not correlated with the residual variables;

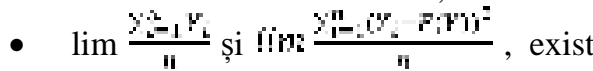
and they are finite (when the number of data is infinite).

\section{Results and disscution. Determinants of interregional movement of labor force in Romania}

The following question arises: what factors generally determine the regional characteristics of migration? We can say that of all the components of the migration, the demographic ones are the most volatile and they interact directly with other domains of the society, as for example: the labor market, political and institutional factors. The non-demographic characteristics can constitute useful information in planning the regional distribution of international migration. For the study of the determinants of interregional migration in Romania, in the first stage of the research, by using the method of principal components and the same econometric techniques, there have been established those regional indices, which have the biggest impact on the movement (evolution) of the population. Thus, there have been used statistic data on some indices - Statistics Annuals of Romania, between 1990 and 2011. By using the statistic software program Eviews, the regressions that quantify the impact of the established variables have been calculated by means of the principal/main components method on Romania's population. From the available statistic data, at this of research, there have been used the following variables: live births, dead-born children, deaths, natural increase, marriages, divorces, infant deaths, registered unemployment (rate) and average net and nominal monthly earnings.

The estimations were achieved by using the method of the least squares, their series being used logarithmically. Because of a reduced number of observations - only 22 , the obtained results must be considered as a prime evaluation of the interdependences between studied variables. The explanation of the dependent variable of the mobility of the labor force is made by means of the 9 independent variables. As a result, the form of the mathematic model will be given by:

$\mathrm{Y}=\mathrm{f}\left(\mathrm{x}_{1}, \mathrm{x}_{2}, \mathrm{x}_{3}, \mathrm{x}_{4}, \mathrm{x}_{5}, \mathrm{x}_{6}, \mathrm{x}_{7}, \mathrm{x}_{8}, \mathrm{x}_{9}\right)$

Where, $F(x)=\alpha+\beta_{1} x_{1}+\beta_{2} x_{2}+\beta_{3} x_{3}+$ $\beta_{4} x_{4}+\beta_{5} x_{5}+\beta_{6} x_{6}+\beta_{7} x_{7}+\beta_{8} x_{8}+\beta_{9} x_{9}$

And we will also presume that this is a 
stochastic relation, which is the form of the econometric model is:

$\mathrm{Y}=\mathrm{f}\left(\mathrm{x}_{1}, \mathrm{x}_{2}, \mathrm{x}_{3}, \mathrm{x}_{4}, \mathrm{x}_{5}, \mathrm{x}_{6}, \mathrm{x}_{7}, \mathrm{x}_{8}, \mathrm{x}_{9}\right)+$ $\varepsilon$,where $\varepsilon$ represents the aleatory variable. Using the OLS method allows us the estimators 'calculus $\hat{\alpha}, \hat{\beta}_{1}, \hat{\beta}_{2}, \hat{\beta}_{3}, \hat{\beta}_{4}, \hat{\beta}_{5}, \hat{\beta}_{6}, \hat{\beta}_{7}, \hat{\beta}_{8}, \hat{\beta}_{9}$ corresponding to parameters $\alpha, \beta 1, \beta 2, \beta 3$, $\beta 4, \beta 5, \beta 6, \beta 7, \beta 8, \beta 9$, so that the function should minimize.

$W=\sum\left(Y-\hat{\alpha}-\hat{\beta}_{1}-\hat{\beta}_{2}-\hat{\beta}_{3}-\hat{\beta}_{4}-\hat{\beta}_{5}-\hat{\beta}_{6}-\hat{\beta}_{7}-\hat{\beta}_{8}-\hat{\beta}_{9}\right)^{2}$

First we are going to analyse statistically the data on: mean, median, minimum and maximum value, standard deviation, indices concerning the asymemetry or flattening of distribution series taken into account. We interpreted a ten series of data, like:

- The indices of asymmetry, Skewness (the independent variable - Deaths presents negative values -4.137891, Registered unemployments 0.227305 , which means that both of them do not inflence the dependent variable to a great extent, while the other independent variables are tightly related to the dependent variables);

- The flattening, Kurtois, the variable divorces, which have a value of $2.813256<3$, mariages, which is $2.923786<3$, and average net and nominal monthly earings $2.484520<$ 3 , show the existence of a certain excess of the diagram of distribution considered to be inferior to that of the normal distribution (flattening), while the other independent variables have a value bigger than 3 , it means/results a certain excess of the diagram of distribution considered superior to that of normal distribution (vaulting/arching).

We can also use the graphic representation for a clear understanding of how the dependent variable depends on all the nine independent variables (figure 3).

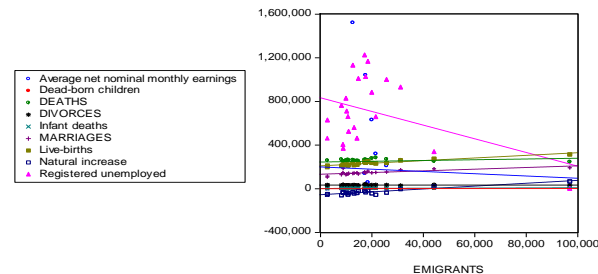

Fig. 3. Linear and negative correlation of the dependent variable

\section{Conclusions}

The estimations have been made by using the method of the least squares, some of the series being used logarithmically.

Due to the reduced number of observations - only 22 , the obtained results must be considered as a prime evaluation of the interdependences between the variables considered.

The analysis of the obtained results points out the fact that the population movement (evolution) is determined by various parameters.

The statistic estimations obtained for each variable indicate the fact that the statistic tests are within admitted limits. All these lead to the necessity that, in the next stages, the data base should be extended with other variables from the socio-economic and environment sector, and also completed with other particular parameters.

It is also required a quarterly assessment of them.

\section{References:}

[1] Demographic Change and Local Development: Shrinkage, Regeneration and Social Dynamics, OECD, 2012, page 11, http://www.oecd.org/countries/roma nia, 04.12.2012.

[2] Labour Market Statistics Data Tables, September 2012,

[3] Statistic Annual of Romania, 2012, (INS) 